\title{
The Molecular Mechanisms Underlying Iron Deficiency Responses in Rice
}

\author{
Qian $\mathrm{Li}^{1,+}$, Lei Chen ${ }^{2}$ and An Yang ${ }^{1, *}$ \\ 1 State Key Laboratory of Vegetation and Environmental Change, Institute of Botany, the Chinese Academy of \\ Sciences, Beijing 100093, China; liqian18@nwafu.edu.cn \\ 2 Guangdong Provincial Key Laboratory of Biotechnology for Plant Development, School of Life Sciences, \\ South China Normal University, Guangzhou 510631, China; chenlei@frontier-ag.com \\ * Correspondence: anyang@ibcas.ac.cn \\ + Current address: College of Horticulture, Northwest A\&F University, Yangling 712100, China.
}

Received: 2 November 2019; Accepted: 17 December 2019; Published: 19 December 2019

check for updates

\begin{abstract}
Iron $(\mathrm{Fe})$ is an essential element required for plant growth and development. Under Fe-deficientconditions, plants have developed two distinct strategies (designated as strategy I and II) to acquire Fe from soil. As a graminaceous species, rice is not a typical strategy II plant, as it not only synthesizes DMA (2'-deoxymugineic acid) in roots to chelate $\mathrm{Fe}^{3+}$ but also acquires $\mathrm{Fe}^{2+}$ through transporters OsIRT1 and OsIRT2. During the synthesis of DMA in rice, there are three sequential enzymatic reactions catalyzed by enzymes NAS (nicotianamine synthase), NAAT (nicotianamine aminotransferase), and DMAS (deoxymugineic acid synthase). Many transporters required for Fe uptake from the rhizosphere and internal translocation have also been identified in rice. In addition, the signaling networks composed of various transcription factors (such as IDEF1, IDEF2, and members of the bHLH (basic helix-loop-helix) family), phytohormones, and signaling molecules are demonstrated to regulate Fe uptake and translocation. This knowledge greatly contributes to our understanding of the molecular mechanisms underlying iron deficiency responses in rice.
\end{abstract}

Keywords: rice (Oryza sativa); Fe deficiency; strategy II; Fe acquisition; transporters; transcription factors; phytohormones

\section{Introduction}

Iron $(\mathrm{Fe})$ is one of the key micronutrients required for various metabolic processes in plants [1,2]. For example, chlorophyll synthesis will be retarded when exposed to an Fe deficiency, leading to interveinal chlorosis in plant leaves and reduced crop yields [1]. Like in plants, Fe is also of great importance for human health. Bioavailable Fe deficiency in food will lead to anemia, one of the top ten health problems in humans at present [3]. It is estimated that at least 2 billion people around the world are affected by Fe-associated anemia, with women of child-bearing age being particularly affected $[1,3]$. Therefore, the biofortification of Fe content in crops will have huge benefits for human health around the world.

Although Fe is the second most abundant metal element in the earth's crust next to aluminum, it mostly exists in the form of insoluble hydroxides and oxides, especially in neutral-to-alkaline soils, which are not bioavailable for plants [4,5]. To cope with low Fe bioavailability in soil, all non-graminaceous monocots and dicots have developed a reduction strategy (named strategy I), while graminaceous plants, including most grain crops, have developed a chelation strategy (named strategy II) [6,7]. In strategy I, $\mathrm{H}^{+}$-ATPases-mediated protons are extruded from the root cell, which leads to the acidification of the rhizosphere and subsequently prompts Fe solubilization $[8,9]$. Then, the ferric iron $\left(\mathrm{Fe}^{3+}\right)$ is reduced to ferrous iron $\left(\mathrm{Fe}^{2+}\right)$ by means of a plasma membrane-located ferric chelate 
enzyme FRO (ferric reductase oxidase) [10]. In strategy I plants, this FRO-catalyzed reduction of $\mathrm{Fe}^{3+}$ to $\mathrm{Fe}^{2+}$ is the rate-limiting step for Fe uptake [10]. Lastly, $\mathrm{Fe}^{2+}$ is transported across the plasma membrane by iron-regulated transporter 1 (IRT1) [11,12]. In strategy II, plants synthesize and secrete mugineic acid (MA) family phytosiderophores in the root to chelate $\mathrm{Fe}^{3+}[13,14]$. Although various MAs exist among different graminaceous species, all MAs are synthesized from S-adenosyl-L-methionine [15-17].

Rice, a graminaceous species, is an important staple crop and feeds more than half of the world's population. However, rice is not a typical strategy II plant. Under conditions of low Fe availability, rice plants can only synthesize DMA ( $2^{\prime}$-deoxymugineic acid) in roots to chelate $\mathrm{Fe}^{3+}$ in the rhizosphere $[13,14]$. In addition, rice is equipped with strategy I to acquire $\mathrm{Fe}^{2+}$, which is mediated by two $\mathrm{Fe}^{2+}$ transporters, OsIRT1 and OsIRT2, in root cells [18]. This is conceivable because rice and its wild relatives need to adapt to waterlogged wetlands, where most iron elements exist as $\mathrm{Fe}^{2+}$ due to the low redox potential $[18,19]$. Although rice plants possess dual Fe acquisition strategies, they are highly susceptible to low Fe conditions in calcareous soils [20,21]. Furthermore, the Fe concentration in polished rice seeds is very low, which cannot satisfy the micronutrient requirements of a human diet [22]. More seriously, the concentration of Fe in rice grains is decreasing by the enriched atmospheric $\mathrm{CO}_{2}$ due to anthropological activities, which will aggravate micronutrient deficiencies in human nutrition in rice-dependent countries [23-25]. To address these problems, we need to biofortify Fe concentrations in rice grains by means of genetic breeding, which relies on determining the mechanisms underlying Fe deficiency responses in rice. Fortunately, a number of genes involved in iron uptake, transport, and regulation have been identified in rice (Table 1). In this review, we summarize the recent progress involved in the Fe signaling networks and homeostasis in rice, and particularly, the detailed knowledge of regulatory roles of phytohormones and messenger molecules in Fe homeostasis.

Table 1. Genes involved in iron (Fe) uptake and transport in rice.

\begin{tabular}{|c|c|c|c|}
\hline Gene Name & Gene ID & Function & References \\
\hline \multicolumn{4}{|c|}{ DMA biosynthesis } \\
\hline OsNAS1 & Os03g0307300 & Nicotianamine synthase & [26] \\
\hline OsNAS2 & Os03g0307200 & Nicotianamine synthase & [26] \\
\hline OsNAS3 & Os07g0689600 & Nicotianamine synthase & {$[26]$} \\
\hline OsNAAT1 & Os02g0306400 & Nicotianamine aminotransferase & [27] \\
\hline OsDMAS1 & Os03g0237100 & Deoxymugineic acid synthase & [28] \\
\hline \multicolumn{4}{|c|}{ Transporters } \\
\hline OsTOM1 & Os11g0134900 & DMA efflux transporter & [29] \\
\hline OsTOM2 & Os11g0135000 & DMA efflux transporter & {$[30]$} \\
\hline OsYSL2 & Os02g0649900 & $\mathrm{Fe}^{2+}-\mathrm{NA}$ transporter & {$[31,32]$} \\
\hline OsYSL9 & Os04g0542200 & $\mathrm{Fe}^{2+}-\mathrm{NA}$ and $\mathrm{Fe}^{3+}-\mathrm{DMA}$ transporter & [33] \\
\hline OsYSL13 & Os04g0524500 & Involved in Fe distribution & [34] \\
\hline OsYSL15 & Os02g0650300 & $\mathrm{Fe}^{3+}$-DMA transporter & [35] \\
\hline OsYSL16 & Os04g0542800 & $\mathrm{Fe}^{3+}$-DMA transporter & [36] \\
\hline OsYSL18 & Os01g0829900 & $\mathrm{Fe}^{3+}$-DMA transporter & {$[37]$} \\
\hline OsFRDL1 & Os03g0216700 & Citrate efflux transporter & [38] \\
\hline OsIRT1 & Os03g0667500 & $\mathrm{Fe}^{2+}$ transporter & [18] \\
\hline OsIRT2 & Os03g0667300 & $\mathrm{Fe}^{2+}$ transporter & [18] \\
\hline PEZ1 & Os03g0571900 & Phenolics efflux transporter & [39] \\
\hline PEZ2 & Os03g0572900 & Phenolics efflux transporter & [40] \\
\hline \multicolumn{4}{|c|}{ Transcription factors } \\
\hline IDEF1 & Os08g0101000 & Positive transcriptional regulator & {$[41,42]$} \\
\hline$I D E F 2$ & Os05g0426200 & Positive transcriptional regulator & [43] \\
\hline OsIRO2 & Os01g0952800 & Positive transcriptional regulator & [44] \\
\hline OsIRO3 & Os03g0379300 & Negative transcriptional regulator & {$[45]$} \\
\hline OsbHLH58 & Os05g0455400, & Positive transcriptional regulator & {$[46,47]$} \\
\hline OsbHLH59 & Os02g0116600, & Positive transcriptional regulator & {$[46,47]$} \\
\hline OsbHLH6O & Os08g0138500 & Positive transcriptional regulator & [48] \\
\hline OsbHLH133 & Os12g0508500 & Negative transcriptional regulator & [49] \\
\hline OsbHLH156 & Os04g0381700 & Positive transcriptional regulator & [50] \\
\hline
\end{tabular}


Table 1. Cont.

\begin{tabular}{cccc}
\hline Gene Name & Gene ID & Function & References \\
\hline OsFRO1 & Os04g0444800 & Other genes & {$[18]$} \\
OsHRZ1 & Os01g0689300 & $\mathrm{Fe}^{3+}$-chelate reductase & {$[51]$} \\
OsHRZ2 & Os05g0551000 & Ubiquitin ligase & {$[51]$} \\
OsHORZ1 & Os01g0861700 & Ubiquitin ligase & {$[51]$} \\
OsIBP1.1 & Os01g0124200 & Bowman-Birk Trypsin Inhibitor & {$[52]$} \\
OsIBP1.2 & Os01g0124400 & Bowman-Birk Trypsin Inhibitor & {$[52]$} \\
OsRab6a & Os03g0191400 & Small GTPase & {$[53]$} \\
OsRMC & Os04g0659300 & Receptor-like protein & {$[54]$} \\
OsCSN6 & Os08g0500000 & COP9 signalosome subunit 6 & {$[55]$} \\
OsIMA1 & Os01g0647200 & Fe-responsive peptides & {$[56]$} \\
\hline
\end{tabular}

\section{Molecular Processes During Iron Acquisition from the Rhizosphere}

In strategy II plants, MA family phytosiderophores are synthesized in vesicles and secreted in the root to chelate $\mathrm{Fe}^{3+}[13,14]$ (Figure 1). Different species and genotypes within a species can differ in the types of MAs secreted in their roots [57]. For example, rice, corn, and wheat secret 2'-Deoxymugineic acid (DMA) to chelate $\mathrm{Fe}^{3+}$, while barley secrets other types of MAs, including MA, 3-hydroxymugineic acid, and 3-epi-hydrdeoxymugineic acid, to chelate $\mathrm{Fe}^{3+}$ [57]. During the synthesis of DMA in rice, three sequential enzymatic reactions are catalyzed by nicotianamine (NA) synthase (NAS), NA aminotransferase (NAAT), and deoxymugineic acid synthase (DMAS) [26-28]. NAS, encoded by three genes (OsNAS1/NAS2/NAS3), is the key enzyme during the synthesis of DMA in rice [26]. Under Fe deficiency conditions, the expression level of genes encoding NAS, NAAT, and DMAS is increased [58,59]. After being synthesized in root cells, DMAs are secreted into the rhizosphere via transporter TOMs (transporter of mugineic acid family phytosiderophores) (Figure 1). The expression levels of TOM1 and TOM2 are induced by Fe-deficient treatment. Alteration to the expression levels of TOM1 or TOM2 in transgenic rice could change the tolerance to Fe deficiency $[29,30]$. Then, $\mathrm{Fe}^{3+}$-DMAs are formed in the rhizosphere and transported into the root cells by YSL (yellow stripe1-like) proteins [60]. YSL proteins are homologous proteins of YS1 (yellow stripe1) in maize. YS1 was first identified in a maize ys1 mutant, which exhibited Fe chlorosis due to the impairment of $\mathrm{Fe}^{3+}$-phytosiderophore uptake [61]. In addition to $\mathrm{Fe}^{3+}$-phytosiderophore uptake, the YSL protein is also involved in $\mathrm{Fe}^{2+}-\mathrm{NA}, \mathrm{Cu}^{2+}-\mathrm{NA}$, and $\mathrm{Mn}^{2+}-\mathrm{NA}$ translocation. In rice, there are 18 genes encoding the YSL transporter. Among these transporters, OsYSL15 and OsYSL16 are involved in Fe ${ }^{3+}$-DMA uptake in rice $[35,36]$. Furthermore, rice can extrude protocatechuic acid (PCA) and caffeic acid (CA) to enhance Fe solubility through the phenolic efflux transporter, OsPEZ2 [40,62] (Figure 1).

Despite being a strategy II plant, rice also absorbs $\mathrm{Fe}^{2+}$ directly via the OsIRTl transporter $[18,63]$ (Figure 1). Moreover, there are two FRO2-like genes, OsFRO1 and OsFRO2, in the rice genome [18]. These two genes were first identified by Ishimaru et al. and possibly have no reductase activities in the rice root [18]. Recently, Li et al. observed that OsFRO1 is localized in the vacuolar membrane in rice protoplasts [64]. They found that OsFRO1 has all the necessary motifs to act as FRO enzyme. In contrast, no complete transmembrane domain exists at the $\mathrm{N}$-terminal of OsFRO2 protein. The concentrations of Fe in the overexpressed OsFRO1 and RNAi lines are higher and lower than that in the wild-type plants under Fe excess conditions, respectively. These results suggest that OsFRO1 could mediate the reduction of $\mathrm{Fe}^{3+}$ to $\mathrm{Fe}^{2+}$ in the vacuole, thus regulating Fe homeostasis in cells [64]. 


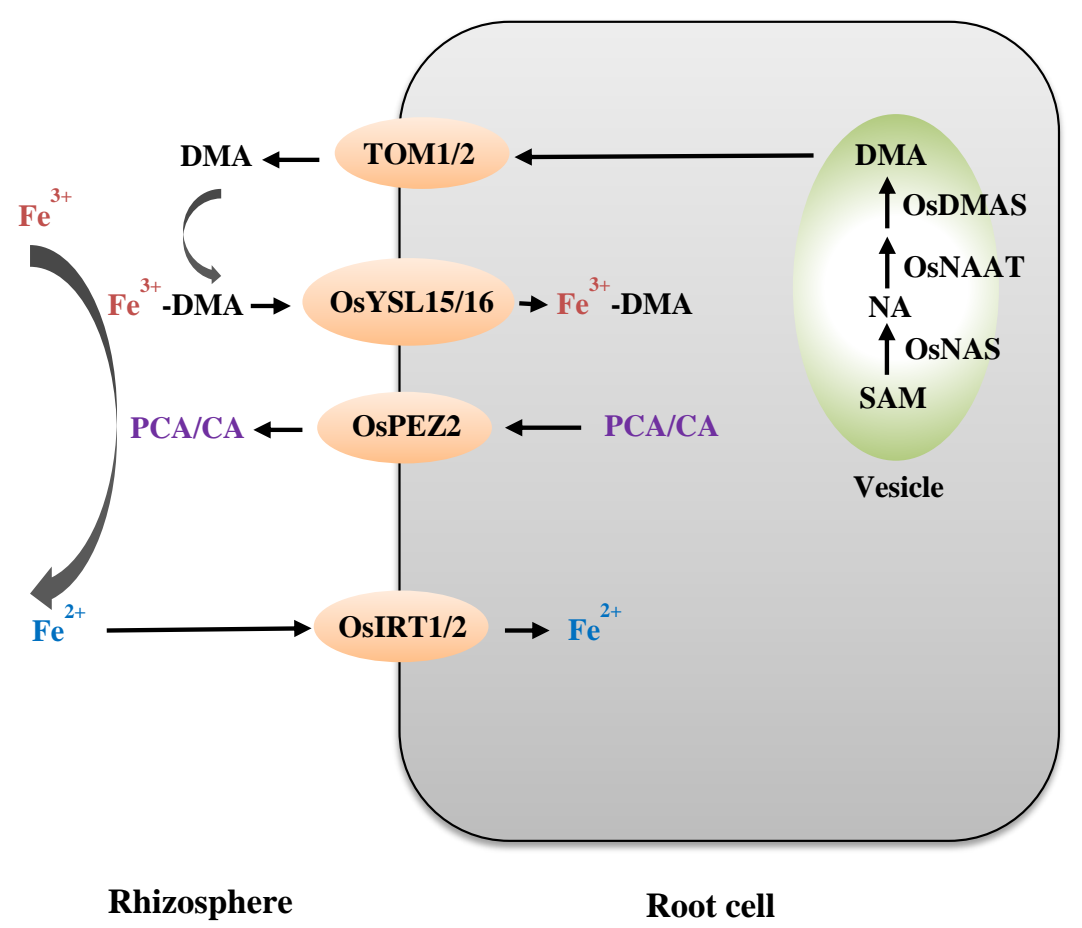

Figure 1. A simplified model of Fe uptake from the rhizosphere in rice. Rice not only synthesizes DMA in roots to chelate $\mathrm{Fe}^{3+}$ but also acquires $\mathrm{Fe}^{2+}$ through transporters OsIRT1 and OsIRT2. During the synthesis of DMA, there are three sequential enzymatic reactions catalyzed by the enzyme, OsNAS, OsNAAT, and OsDMAS. The TOM (transporter of mugineic acid family phytosiderophores) and OsYSL transporters are required for Fe uptake from the rhizosphere. OsPEZ2s are phenolic efflux transporters responsible for the transport of protocatechuic acid/caffeic acid (PCA/CA). The root cell is shown in the grey rounded rectangle. The vesicle is shown in the light green ellipse. Transporters are shown in the light orange ellipses.

\section{Internal Iron (Fe) Translocation}

Once absorbed at the root's surface, Fe is radially transported across the root epidermis, cortex, and pericycle to reach the xylem parenchyma cell, where Fe is unloaded into the xylem vessels by Fe transporters $[8,65]$. Due to its low solubility and toxicity to cells, Fe needs to be complexed with a suitable chelator within the plant body. Citrate [66,67], NA [68], and MAs [37] are demonstrated to be the main chelators that bind Fe in plants. Citrate plays a dominant role in the chelating and trafficking of Fe in xylem sap in some plants, such as soybean, tomato, rice, and Arabidopsis $[66,69]$. In recent years, the transporters of citrate have been identified. By analyzing the Arabidopsis mutant, frd3, AtFRD3, a member of the multidrug and toxic compound extrusion (MATE) family, was shown to play an important role in xylem Fe transport. Compared with wild-type plants grown on Fe-sufficient media, an frd3 mutant grown under identical conditions exhibits chlorotic leaves and a significant reduction of citrate and Fe in the xylem exudate. Furthermore, the phenotypes of frd 3 mutants can be rescued when grown on citrate-supplemented media. These results suggest that AtFRD3 is involved in loading citrate in the xylem. OsFRDL1, an AtFRD3-like gene in rice, encodes a citrate effluxer that is specifically expressed in root pericycle cells $[38,70]$. The expression of OsFRDL1 shows no obvious responses to Fe deficiency treatment. Osfrdl1 mutants exhibit Fe deficiency-induced chlorosis due to lower Fe concentrations in their leaves, and the amounts of citrate and ferric iron in the xylem sap of osfrdl mutants was also less than the amounts in the wild-type rice [70]. When grown under Fe-deficient conditions, osfrdl mutants contain much greater Fe concentrations in their roots compared to wild-type rice [70]. Using the Perls blue staining method, $\mathrm{Fe}^{3+}$ was observed to deposit in the root stele of osfrdl mutants [70]. At the stage of reproduction, Yokosho et al. reported that OsFRDL1 shows significant expression in the upper nodes of rice plants. The pollen viability and grain yield 
of the Osfrdl1 mutant was reduced, which may be accounted for by the enhanced Fe precipitation in node I and the impaired distribution of Fe to the panicles [71]. These results suggest that OsFRDL1 functions during the translocation of Fe from roots to shoots in the period of vegetative growth, as well as during the distribution of Fe to panicles at the period of reproduction (Figure 2). To solubilize the deposited apoplasmic Fe, various phenolics, including PCA and CA, are extruded in plants [39,40]. In rice, OsPEZ1 and OsPEZ2 are identified as two phenolic efflux transporters (Figure 2). These two transporters can facilitate loading phenolics into the xylem, thus prompting the utilization of deposited apoplasmic Fe from root surfaces into the stele. Overexpression of OsPEZ1 leads to Fe toxicity phenotypes, as evidenced by severely reduced growth and leaf-tip necrosis, which are attributed to the increased contents of Fe in plants body under Fe-replete conditions [39,40]. ospez1/2 mutants have higher amounts of apoplasmic Fe in roots, thereby exhibiting a greater tolerance to Fe-deficient conditions than wild-type rice plants $[39,40]$.

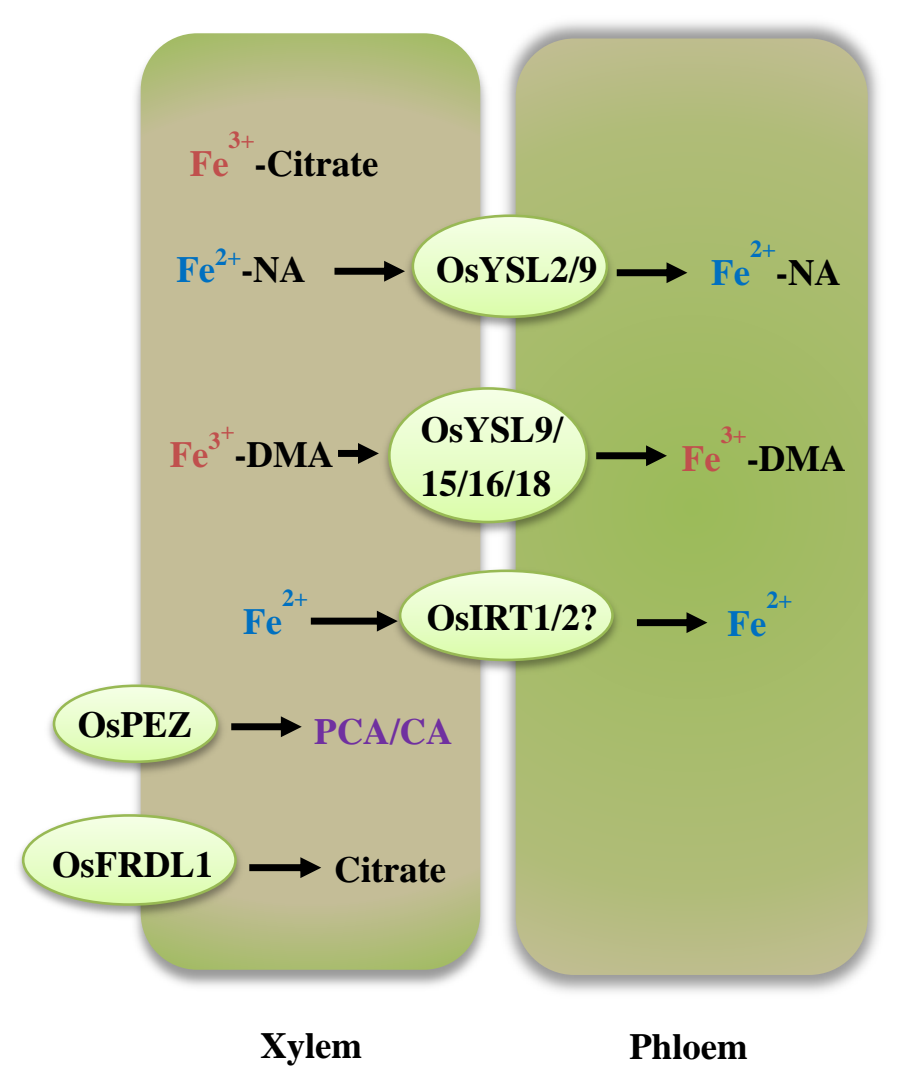

Figure 2. A simplified model of internal Fe translocation in rice. Citrate, NA, and DMA are the main chelators used to bind Fe within rice. OsFRDL1 encodes a citrate effluxer. OsYSL transporters are responsible for the translocation of $\mathrm{Fe}^{3+}$-DMA and $\mathrm{Fe}^{2+}$-NA from xylem to phloem. Xylem and phloem are shown in rounded rectangles. Transporters are shown in light green ellipses.

After Fe is loaded into xylem sap, a part of the Fe will be unloaded into the phloem cell, through which Fe is transported to various plant tissue [67]. An iron transporter is necessary for this process. In recent years, the YSL family has been reported to not only facilitate $\mathrm{Fe}^{3+}$-DMA uptake from the rhizosphere but is also involved in iron unloading into the phloem [60]. OsYSL2 is a member of the YSL family and is required to transport $\mathrm{Fe}^{2+}-\mathrm{NA}$ and $\mathrm{Mn}^{2+}-\mathrm{NA}$ but not $\mathrm{Fe}^{3+}$-DMA. The expression of OsYSL2 is detected in phloem cells and developing seeds [31]. By analyzing transgenic plants with altered expression levels, OsYSL2 has been shown to affect the distribution of Fe within the plants [31,32]. Collectively, these results suggest that OsYSL2 is a pivotal $\mathrm{Fe}^{2+}-\mathrm{NA}$ transporter mediating the phloem transport of Fe in rice [31,32]. OsYSL9 also belongs to the YSL transporter family and is responsible for the transport of both $\mathrm{Fe}^{2+}-\mathrm{NA}$ and $\mathrm{Fe}^{3+}$-DMA across the plasma membrane. Treatment with 
Fe deficiency increases the expression of OSYSL9 in the central cylinder instead of the epidermis. OsYSL9 RNAi transgenic rice is less tolerant to Fe deficiency than wild-type rice plants, as evidenced by their shorter shoot lengths and the lower concentrations of chlorophyll and Fe in their leaves. In particular, knocking down the expression of OsYSL9 reduces and improves the concentration of Fe in embryos and brown seeds without embryos. These results suggest that OsYSL9 participates in iron translocation within the rice plant body, especially in developing seeds [33]. Recently, another YSL transporter, OsYSL13, was reported to regulate the translocation of Fe to younger leaves and seeds in rice [34]. OsYSL15 is a $\mathrm{Fe}^{3+}$-DMA transporter and play a critical role in Fe uptake from the rhizosphere. The expression of OsYSL15 is detected in vascular bundles and developing seeds, implying that OsYSL15 may be responsible for the translocation of Fe in the phloem and loading of seeds [35,72]. OsYSL16 is highly similar to OsYSL2 and OsYSL15 and has the ability to acquire $\mathrm{Fe}^{3+}$-DMA from the rhizosphere. In addition, OsYSL16 is highly expressed in vascular bundles and mediates the internal distribution of $\mathrm{Fe}^{3+}$-DMA in rice $[36,73]$. The osysl16 mutants tend to deposit $\mathrm{Fe}$ mainly in the veins and are less tolerant to Fe deficiency than wild-type plants [36,73]. OsYSL18 is also localized in the plasma membrane with the function of translocating $\mathrm{Fe}^{3+}$-DMA. OsYSL18 is reported to take part in the transport of Fe inside the reproductive organs and joins the phloem of rice [37]. Like OsYSL15, the expression of TOM1 and OSIRT1 can be detected in the vascular tissues of rice plants, which indicates that these two transporters function in the Fe acquisition from the rhizosphere, as well as internal Fe distribution [18,29] (Figure 2).

\section{Regulation of Fe Deficiency Responsive Genes}

To maintain Fe homeostasis, plants develop a signaling network to regulate iron absorption and transport. There are two cis-acting elements, IDE1 and IDE2, which exist at the promoters of Fe deficiency responsive genes in a number of plant species. In rice, two transcription factors, IDEF1 and IDEF2, have been identified to specifically bind IDE1 and IDE2, respectively [41,43] (Figure 3). IDEF1 belongs to the ABI3/VP1 (abscisic acid insensitive 3/viviparous 1) transcription factor, while IDEF2 is a member of the transcription factor NAC family [41,43]. The constitutive expression of IDEF1 and IDEF2 is detected in vegetative and reproductive tissues [42,43,74]. The genes responsible for Fe uptake and translocation are regulated by IDEF1 under Fe-sufficient conditions, as well as in the early stages of Fe deficiency. At subsequent stages of Fe deficiency, IDEF1 can affect the expression of LEA (late embryogenesis abundant) genes by binding the RY cis element (CATGCA) [42]. In addition, IDEF1 is thought to be an Fe sensor due to its ability to directly bind Fe via the metal-binding domain, which is essential for the Fe deficiency signaling cascade [75]. In contrast to IDEF1, the target genes of IDEF2 are not altered during the processes of Fe-deficiency [74]. IDEF2 is required for the expression of a number of Fe deficiency-induced genes. In addition, OsYSL2 has been shown to be the target gene of IDEF2, which recognizes IDE2 sties in the promoter of OsYSL2. The IDEF2 knockdown transgenic rice exhibits abnormal Fe allocation between the shoots and roots [74].

OsHRZ1 and OsHRZ2 are also regraded as candidates for Fe sensors because they directly bind Fe via hemerythrin domains. OsHRZ1 and OsHRZ2 also have RING (really interesting new gene) Zn-finger domains that act as E3 ubiquitin ligases [51,76]. OsHRZ1 and OsHRZ2 RNAi rice plants show enhanced tolerance to Fe deficiency treatment compared to wild-type rice plants, coupled with the increased contents of Fe in shoots and grains, as well as Fe deficiency responsive genes [51,76]. Thus, OsHRZ1 and OsHRZ2 are assumed to negatively modulate the responses of rice to Fe deficiency (Figure 3). Additionally, the expression of both OsHRZ1 and OsHRZ2 is under the control of IDEF1 in rice. OsHORZ1 is also a protein that contains the hemerythrin domain and is suggested to repress OsHRZ functions [51,76].

OsIBP1.1 and OsIBP1.2 are Bowman-Birk trypsin inhibitors, which can interact with IDEF1 and thus prevent the 26S proteasome-mediated degradation of IDEF1 (Figure 3). Fe-deficient treatments induce the expression of OsIBP1.1 and OsIBP1.2 via IDEF1. An overexpression of OsIBP1.1 markedly increases the expression of OsYSL2 in rice [52]. The OsCOP9 complex consists of eight subunits 
involved in the ubiquitin-proteasome degradation processes. Among these eight subunits, OsCSN6 is repressed at an early stage of Fe deficiency in rice, which decreases the activity of the OsCOP9 complex. Knockdown of OsCSN6 leads to the accumulation of IDEF1, which subsequently enhances Fe-related genes at early stages of Fe deficiency in rice [55].

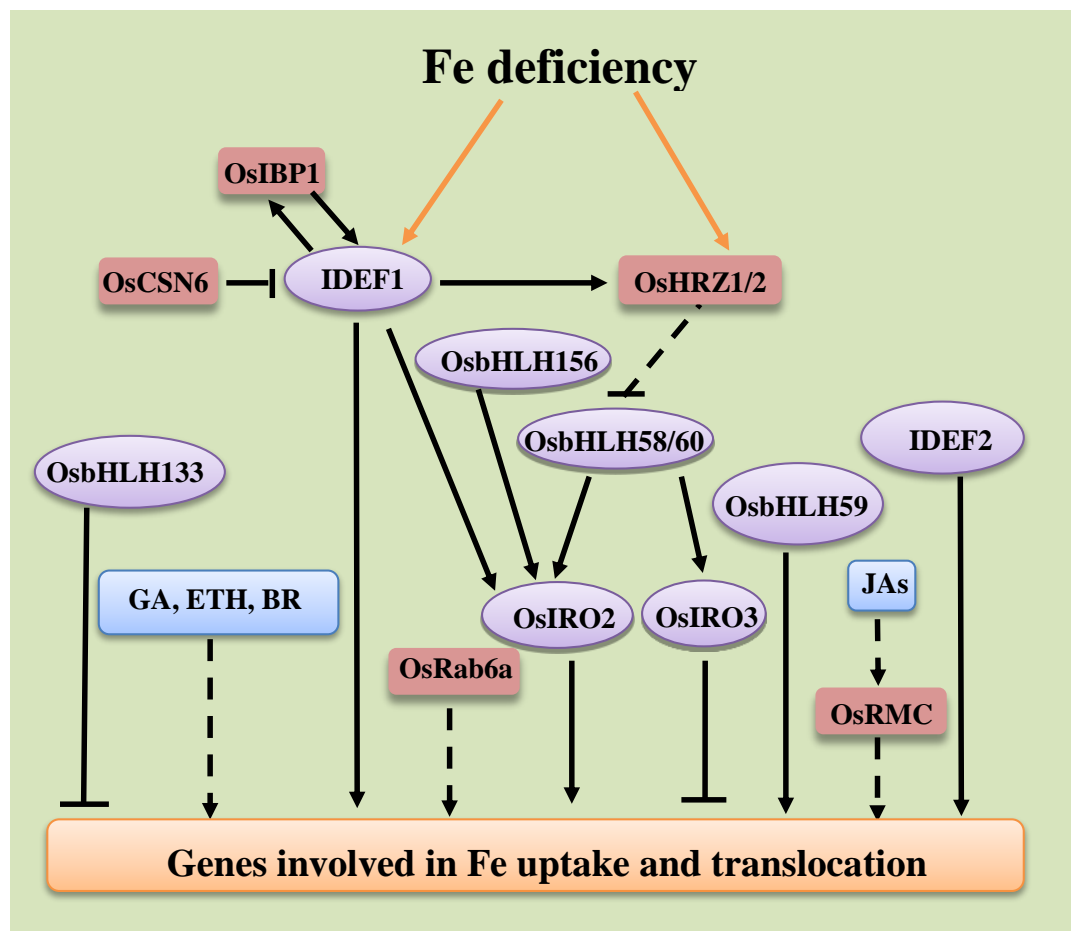

Figure 3. The regulatory networks of the genes involved in Fe uptake and translocation in rice roots. Transcription factors are shown in light purple ellipses. Other regulatory proteins are shown in pink rounded rectangles. Hormones and signaling molecules are shown in light blue rounded rectangles. The genes involved in Fe uptake and translocation are shown in light orange rounded rectangles. Positive regulation is indicated by black arrows. Negative regulation is indicated by black blunt arrows. Broken lines indicate regulation with unknown mechanisms. Orange lines indicate that Fe signals are sensed by IDEF1, OsHRZ1, and OsHRZ2.

The bHLH (basic helix-loop-helix) transcription factor family plays a critical role in the regulation of Fe-deficiency response genes in both strategy I and strategy II plants [60]. In rice, there are several bHLH transcription factors that have been characterized to be regulators of Fe homeostasis (Figure 3). Among them, OsIRO2 is a well-studied bHLH transcription factor in rice [44]. The overexpression of OsIRO2 in rice increases MA secretion and Fe content in shoots, and thus improves the tolerance of rice plants to Fe deficiency $[77,78]$. A microarray analysis shows that the interaction between OsIRO2 and IDEF1 positively modulates many Fe deficiency responsive genes, and its expression may be regulated by IDEF1 [41,42]. OsIRO3 is also a bHLH transcription factor and is identified as a negative regulator of Fe utilization genes. OsIRO3-overexpression rice plants are very sensitive to Fe deficiency treatment because of their reduction in the expression of genes involved in Fe uptake and translocation [45]. Another bHLH transcription factor, OsbHLH133, has been demonstrated to play a negative regulatory role in the distribution of Fe between the shoots and roots of rice plants. Specifically, the osbhlh133 mutant exhibits decreased Fe concentrations in its shoots and increased Fe concentration in its roots due to its higher expression of the genes involved in Fe uptake and translocation than wild-type plants [49]. However, the Fe concentration in the shoots and xylem sap of OsbHLH133-overexpressing rice plants is suppressed while the Fe concentration in roots is improved [49]. OsbHLH156 is found to positively regulate Fe deficiency response genes by facilitating nuclear localization of OsIRO2 [50]. There are four members of the IVc bHLHs subgroup in rice, OsbHLH57, OsbHLH58, OsbHLH59, and 
OsbHLH60 [46-48]. Zhang et al. reported that OsbHLH60 (also named OsPRI1) positively modulates the responses of rice to Fe deficiency [48]. Compared to wild-type plants, osphr1 mutants exhibit less tolerance to Fe deficiency due to their inhibited expression of Fe deficiency inducible genes. OsPRI1 is found to interact with, and suggested to be ubiquitinated by, OsHRZ1. The knockout of OsPRI1 can decrease the tolerance of $o s h r z 1$ mutants to Fe deficiency. Furthermore, OsPRI1 acts upstream of OsIRO2 and OsIRO3. Taken together, a signaling pathway underlying the regulation of Fe deficiency responses is proposed as OsHRZ1-OsPRI1-OsIRO2/3 [48]. Kobayashi et al. found that OsbHLH58 and OsbHLH59 are two positive regulators of Fe responses, such that the knockout of these two transcription factors decreases the expression of Fe deficiency response genes and impairs the tolerance of rice plants to Fe deficiency treatments [46]. They uncovered strong interactions between OsbHLH58 and OsHRZs (OsHRZ1 and OsHRZ2) and no interaction between OsbHLH59 and OsHRZs. OsbHLH58, OsbHLH59, and OsbHLH60 were not found to be ubiquitinated by OsHRZs [46]. OsbHLH57 is also induced by Fe deficiency in the shoots and roots of rice plants [46]. A detailed study of OsbHLH057 in rice responses to Fe deficiency is warranted. Recently, Zhang et al. reported partially inconsistent results with those of Kobayashi et al. They found that OsHRZ1 directly interacts with OsbHLH058 and OsbHLH059 and promotes their degradation [47]. These inconsistent results may be due to the different experimental methods used in these studies.

OsRab6a and OsRMC are also regulators of Fe-deficient responses (Figure 3). OsRab6a is a small GTPase in rice [53]. Under Fe-deficient conditions, OsRab6a overexpression lines have higher Fe concentrations in the shoots and roots of grains by up-regulating OsIRO2, OsIRT1, OsNAS1, and OsNAS2, suggesting that OsRab6a plays an important role in the regulation of Fe acquisition in rice plants [53]. OsRMC is a receptor-like protein, which was previously found to be involved in JA (jasmonic acid)-mediated root development. Through comparison with wild-type and transgenic plants under Fe-deficient conditions, OsRMC is shown to be a positive regulator of Fe uptake in rice [54]. IMA (IRON MAN, a short C-terminal amino-acid sequence consensus motif) genes encode Fe-responsive peptides in the phloem. There are two IMA genes in rice, OsIMA1 and OsIMA2. The heterologous expression of OsIMA1 in arabidopsis increases the Fe concentration in rosettes by promoting FCR (ferric-chelate reduction) activity under Fe-sufficient conditions [56].

\section{Regulatory Roles of Phytohormones and Messenger Molecules in Fe Homeostasis}

Various phytohormones and messenger molecules have been demonstrated to regulate the Fe deficiency responses in rice. The following section presents a compilation of emerging information on the functions of phytohormones and messenger molecules in responding to Fe deficiency in rice (Figure 3).

\subsection{Brassinosteroids (BRs)}

Brassinosteroids (BRs) are a type of steroid hormone that plays an important role in plant growth and development [79]. Emerging studies shed light on the regulatory roles of BR in maintaining Fe homeostasis in plants. Wang et al. reported that BRs participate in the regulation of Fe deficiency responses in cucumber (Cucumis sativus). They found that BRs may negatively modulate Fe homeostasis by reducing Fe deficiency-induced FRO activities, the expression level of two Fe deficiency responsive genes (CSFRO1 and CSIRT1), and the Fe translocation from root to shoot in cucumbers (Cucumis sativus) [80]. Then, these researchers found that BRs are also involved in the responses of rice to Fe deficiency at the physiological and molecular level. Specifically, the exogenous application of EBR (24-epibrassinolide, a brassinosteroid) can produce more evident chlorosis in rice leaves and reduce the growth of seedlings under Fe deficiency conditions. In addition, EBR changes the translocation of Fe in the phloem, leading to a greater accumulation of Fe in the roots under both Fe-sufficient and Fe-deficient conditions. These responses of rice treated with EBR under Fe deficiency conditions can be accounted for by the expression patterns of Fe-deficient responsive genes, such that, in the roots, 
OsIRT1, OsYSL15, OsYSL2, OsNAS1, and OsNAS2 are induced by EBR, while in shoots, the genes OsYSL2, OsNAS1, and OsNAS2 are suppressed by EBR under Fe-deficient conditions [81].

\subsection{Gibberellins (GAs)}

Gibberellins (GAs) are a classical type of phytohormone that functions in the regulation of various aspects of physiological processes [82]. In arabidopsis, GA signaling is found to be involved in Fe deficiency responses by positively modulating the expression of the Fe-uptake gene [83]. However, there is limited information available on the involvement of GAs in the regulation of Fe homeostasis in rice. The protein OsEUI (elongated uppermost internode) is a GA-deactivating enzyme, and a mutation of this gene leads to an increase in the GA concentration in rice. By comparing wild-type with eui mutant and EUI overexpression lines, GA is demonstrated to be involved in the responses of rice to Fe deficiency by negatively modulating Fe transport and translocation from root to shoots. Treatment with GA could exaggerate leaf chlorosis and suppress growth, which is attributed to the reduction of Fe concentration in leaves under Fe deficiency conditions. In wild-type roots, some Fe deficiency responsive genes including OsIRO2, OsNAAT1 and OsYSL15 are induced by GA treatment under Fe deficiency. The concentration of Fe in the shoots of the EUI overexpression line and oseui mutant is higher and lower than that of the wild-type plants, respectively. In addition, the retardation of Fe translocation in the shoots of the oseui mutant may be due to a decrease in the OsYSL2 expression level [84].

\subsection{Jasmonates (JAs)}

Jasmonates (JAs), includingJA, and their biologically active derivatives, are synthesized from $\alpha$-linolenic acid in plants when exposed to biotic and abiotic stresses [85,86]. In arabidopsis, JA was discovered to suppress IRT1 and FRO2 expression when exposed to Fe deficiency [87]. Some studies have provided new insights into the involvement of JAs in the responses of rice to Fe deficiency. $O s R M C$ encodes a receptor-like protein and can alter root development by targeting the JA signaling pathway. Our study demonstrates that the overexpression of OsRMC enhances Fe concentration and upregulates the expression level of Fe deficiency-related genes, including OsDMAS1, OsNAS1, OsNAS2, OsNAAT1, OsIRT1, OsYSL15, and OsIRO2 in rice seedlings [54]. OsIBP1.1 and OsIBP1.2 are Bowman-Birk trypsin inhibitors and can bind the transcription factor IDEF1. The expressions of these two homologous genes are induced by Fe deficiency, as well as by the exogenous application of JA $[52,88]$. Kobayashi et al. investigated the regulatory roles of JA in the responses to Fe deficiency in rice roots. They found that very early Fe deficiency could rapidly increase the concentration of endogenous JAs and activate the JA signaling pathways via OsHRZs and IDEF1 in rice roots. cpm2 is a rice JA-deficient mutant. By comparing cpm2 and the wild-type, JA was shown to down-regulate Fe deficiency responsive genes under Fe-sufficient conditions, but this downregulation could be ameliorated under Fe deficiency conditions [89]. Taken together, these results suggest that JA plays a positive role in the regulation of Fe uptake and translocation during early periods of Fe deficiency treatment in rice roots [89].

\subsection{Ethylene}

Ethylene is a gaseous hormone that plays very important roles in plant growth and development [90]. Recently, ethylene was reported to be involved in the regulation of Fe deficiency responses in rice [91,92]. When exposed to Fe-starvation conditions, the expression levels of several ethylene biosynthesis-related genes encoding ACS (1-aminocyclopropane-1-carboxylic acid (ACC) synthases) and ACO (ACC oxidases), as well as the production of ethylene, are significantly enhanced in the roots of rice plants [92,93]. The exogenous application of the ethylene precursor ACC (1-aminocyclopropane-1-carboxylic acid) could increase the concentration of soluble Fe in rice seedlings to alleviate Fe deficiency-induced leaf chlorosis. The genes involved in Fe acquisition are significantly induced by ethylene under Fe-depleted conditions but are repressed by ethylene inhibitors, such 
as $\mathrm{Co}^{2+}$ and STS (silver thiosulphate). An analysis of OsIRO2 RNAi transgenic rice reveals that the upregulation of OsNAS1, OsNAS2, OsYSL15, and OsIRT1 by ethylene treatment is dependent on OsIRO2 [92].

\subsection{Sucrose}

As the main product of plant photosynthesis, sucrose acts as an energy resource for growth and development, as well as a signaling substance that participates in the responses of plants to biotic and abiotic stresses, such as mineral starvation [94,95]. In rice, sucrose is found to take part in modulating Fe deficiency responses [94]. A greater amount of sucrose tends to accumulate in the leaves rather than in the roots of rice plants when grown under Fe-deficient conditions by suppressing the transcript abundance of SUT (sucrose transporter) genes in leaves. Additionally, the exogenous application of sucrose and a reduction in endogenous sucrose concentrations by dark treatment led to opposite expression patterns for Fe-related genes in roots and leaves under Fe deficiency conditions. These results highlight that sucrose functions as a shoot-generated signaling substance mediating shoot-root communication in the responses of rice plants to Fe deficiency [94].

\subsection{Auxin}

Auxin has also been proven to participate in the responses of rice to Fe deficiency. Liu et al. found that treatment with auxin exaggerates the Fe deficiency characteristics in rice [96]. This auxin signaling is responsible for the suppression of growth and the photosynthesis of rice plants when subjected to Fe-deficient treatments [96]. In addition, some auxin response-related genes have been shown to participate in the crosstalk between auxin signaling and Fe deficiency responses. OsABCB14, an ATP Binding Cassette B/Multidrug-Resistance/P-glyco-protein (ABCB/MDR/PGP) regulating auxin transport, affects Fe acquisition in rice [97]. ARF (auxin response factor) belongs to multiple gene families and mediates the actions of auxins. Based on an analysis of the osarf12 mutant, the transcription factor OsARF12 could alter Fe accumulation via regulation of the OsIRT1 in rice [98]. Transcription factor OsARF16 is another member of the ARF family, which has been reported to adjust auxin redistribution and Fe deficiency responses in rice [99].

\subsection{Nitric Oxide (NO)}

Nitric oxide (NO) plays a critical role in the regulation of Fe deficiency responses in plants [100]. However, less attention is paid to the function of NO in the Fe uptake of strategy II plants compared to the great number of studies on strategy I plants [100]. Recently, Sun et al. observed that NO is produced by the NO synthase-like pathway and acts downstream of auxin to modify root growth under Fe deficiency conditions [101]. Moreover, Zhu et al. reported that NO mediates cell wall Fe reutilization when rice plants grow under Fe deficiency conditions in the presence of $\mathrm{NH}_{4}{ }^{+}$[102].

\subsection{Abscisic Acid (ABA)}

Abscisic acid (ABA) is a well-documented plant hormone that plays important roles in responses to multifaceted stresses [103]. In Arabidopsis, ABA was shown to alleviate leaf chlorosis symptoms via the reutilization of root $\mathrm{Fe}$ and the translocation of Fe from root to shoot under Fe deficiency. In contrast, only limited clues indicate the role of $\mathrm{ABA}$ in response to Fe deficiency in rice [41,42]. As mentioned above, IDEF1 is a member of the ABI3/VP1 transcription factor family participating in the ABA response in plants [41]. In addition, several ABA-responsive genes are induced by $\mathrm{Fe}$ deficiency through IDEF1 in rice [42].

\subsection{Cytokinins (CKs) and Salicylic Acid (SA)}

Cytokinins (CKs) play a negative role in the modulation of the iron acquisition process in the root of Arabidopsis [104]. Salicylic acid (SA) is another phytohormone that is also reported to be involved 
in the regulation of Fe homeostasis in Arabidopsis [105]. However, to the best of our knowledge, no research has been conducted to investigate the roles of CKs and SA in the responses of rice to Fe-deficient conditions.

\section{Conclusions}

Rice is highly susceptible to Fe deficiency in soil and accumulates relatively low amounts of Fe in polished seeds, which threatens human health. In this review, the molecular mechanisms modulating Fe homeostasis in rice were summarized. Over the past years, great progress has been made to identify the genes responsible for Fe uptake, translocation, and reutilization in rice. In addition, phytohormone and signaling molecules have also been demonstrated to play important roles in the regulation of Fe deficiency response genes in rice. Despite this progress, more efforts are still needed to understand the mechanisms underlying the responses of rice to Fe deficiency at the transcriptional and post-transcriptional levels. These efforts will subsequently facilitate Fe biofortification in rice grains via molecular breeding methods

Author Contributions: A.Y. conceived the idea., and Q.L. and A.Y. wrote the manuscript with help from L.C. All authors have read and agreed to the published version of the manuscript.

Funding: This work was supported by the National Key Research and Development Program of China (2016YFC0500706), the National Natural Science Foundation of China (31801280 and 31301832), and the China Postdoctoral Science Foundation (2018M633039).

Conflicts of Interest: The authors declare no conflict of interest.

\section{References}

1. Briat, J.F.; Dubos, C.; Gaymard, F. Iron nutrition, biomass production, and plant product quality. Trends Plant Sci. 2015, 20, 33-40. [CrossRef] [PubMed]

2. Haensch, R.; Mendel, R.R. Physiological functions of mineral micronutrients $(\mathrm{Cu}, \mathrm{Zn}, \mathrm{Mn}, \mathrm{Fe}, \mathrm{Ni}, \mathrm{Mo}, \mathrm{B}, \mathrm{Cl})$. Curr. Opin. Plant Biol. 2009, 12, 259-266. [CrossRef] [PubMed]

3. Murgia, I.; Arosio, P.; Tarantino, D.; Soave, C. Biofortification for combating 'hidden hunger' for iron. Trends Plant Sci. 2012, 17, 47-55. [CrossRef] [PubMed]

4. Guerinot, M.L.; Yi, Y. Iron: Nutritious, noxious, and not readily available. Plant Physiol. 1994, 104, 815-820. [CrossRef] [PubMed]

5. Romera, F.J.; Alcantara, E. Ethylene involvement in the regulation of Fe-deficiency stress responses by Strategy I plants. Funct. Plant Biol. 2004, 31, 315-328. [CrossRef]

6. Marschner, H.; Römheld, V.; Kissel, M. Different strategies in higher plants in mobilization and uptake of iron. J. Plant Nutr. 1986, 9, 695-713. [CrossRef]

7. Mori, S. Iron acquisition by plants. Curr. Opin. Plant Biol. 1999, 2, 250-253. [CrossRef]

8. Kawakami, Y.; Bhullar, N.K. Molecular processes in iron and zinc homeostasis and their modulation for biofortification in rice. J. Integr. Plant Biol. 2018, 60, 1181-1198. [CrossRef]

9. Santi, S.; Schmidt, W. Dissecting iron deficiency-induced proton extrusion in Arabidopsis roots. New Phytol. 2009, 183, 1072-1084. [CrossRef]

10. Robinson, N.J.; Procter, C.M.; Connolly, E.L.; Guerinot, M.L. A ferric-chelate reductase for iron uptake from soils. Nature 1999, 397, 694-697. [CrossRef]

11. Brumbarova, T.; Bauer, P.; Ivanov, R. Molecular mechanisms governing Arabidopsis iron uptake. Trends Plant Sci. 2015, 20, 124-133. [CrossRef] [PubMed]

12. Eide, D.; Broderius, M.; Fett, J.; Guerinot, M.L. A novel iron-regulated metal transporter from plants identified by functional expression in yeast. Proc. Natl. Acad. Sci. USA 1996, 93, 5624-5628. [CrossRef] [PubMed]

13. Römheld, V.; Marschner, H. Evidence for a specific uptake system for iron phytosiderophores in roots of grasses. Plant Physiol. 1986, 80, 175-180. [CrossRef] [PubMed]

14. Takagi, S.-I. Naturally occurring iron-chelating compounds in oat-and rice-root washings: I. Activity measurement and preliminary characterization. Soil Sci. Plant Nutr. 1976, 22, 423-433. [CrossRef]

15. Kawai, S.; Takagi, S.I.; Sato, Y. Mugineic acid-family phytosiderophores in root-secretions of barley, corn and sorghum varieties. J. Plant Nutr. 1988, 11, 633-642. [CrossRef] 
16. Mori, S.; Nishizawa, N. Methionine as a dominant precursor of phytosiderophores in Graminaceae plants. Plant Cell Physiol. 1987, 28, 1081-1092.

17. Shojima, S.; Nishizawa, N.-K.; Fushiya, S.; Nozoe, S.; Irifune, T.; Mori, S. Biosynthesis of phytosiderophores: In vitro biosynthesis of 2'-deoxymugineic acid from L-methionine and nicotianamine. Plant Physiol. 1990, 93, 1497-1503. [CrossRef]

18. Ishimaru, Y.; Suzuki, M.; Tsukamoto, T.; Suzuki, K.; Nakazono, M.; Kobayashi, T.; Wada, Y.; Watanabe, S.; Matsuhashi, S.; Takahashi, M.; et al. Rice plants take up iron as an $\mathrm{Fe}^{3+}$-phytosiderophore and as $\mathrm{Fe}^{2+}$. Plant J. 2006, 45, 335-346. [CrossRef]

19. Cheng, L.; Wang, F.; Shou, H.; Huang, F.; Zheng, L.; He, F.; Li, J.; Zhao, F.-J.; Ueno, D.; Ma, J.F.; et al. Mutation in nicotianamine aminotransferase stimulated the $\mathrm{Fe}(\mathrm{II})$ acquisition system and led to iron accumulation in rice. Plant Physiol. 2007, 145, 647-1657. [CrossRef]

20. Mori, S.; Nishizawa, N.; Hayashi, H.; Chino, M.; Yoshimura, E.; Ishihara, J. Why are young rice plants highly susceptible to iron-deficiency. Plant Soil 1991, 130, 143-156. [CrossRef]

21. Morrissey, J.; Guerinot, M.L. Iron uptake and transport in plants: The good, the bad, and the ionome. Chem. Rev. 2009, 109, 4553-4567. [CrossRef] [PubMed]

22. Bouis, H.E.; Hotz, C.; McClafferty, B.; Meenakshi, J.V.; Pfeiffer, W.H. Biofortification: A new tool to reduce micronutrient malnutrition. Food Nutr. Bull. 2011, 32, 31-40. [CrossRef] [PubMed]

23. Loladze, I. Hidden shift of the ionome of plants exposed to elevated $\mathrm{CO}_{2}$ depletes minerals at the base of human nutrition. eLife 2014, 3, e02245. [CrossRef]

24. Myers, S.S.; Zanobetti, A.; Kloog, I.; Huybers, P.; Leakey, A.D.B.; Bloom, A.J.; Carlisle, E.; Dietterich, L.H.; Fitzgerald, G.; Hasegawa, T.; et al. Increasing $\mathrm{CO}_{2}$ threatens human nutrition. Nature 2014, 510, 139-142. [CrossRef] [PubMed]

25. Zhu, C.; Kobayashi, K.; Loladze, I.; Zhu, J.; Jiang, Q.; Xu, X.; Liu, G.; Seneweera, S.; Ebi, K.L.; Drewnowski, A. Carbon dioxide $\left(\mathrm{CO}_{2}\right)$ levels this century will alter the protein, micronutrients, and vitamin content of rice grains with potential health consequences for the poorest rice-dependent countries. Sci. Adv. 2018, 4 . [CrossRef]

26. Higuchi, K.; Watanabe, S.; Takahashi, M.; Kawasaki, S.; Nakanishi, H.; Nishizawa, N.K.; Mori, S. Nicotianamine synthase gene expression differs in barley and rice under Fe-deficient conditions. Plant $J$. 2001, 25, 159-167. [CrossRef]

27. Inoue, H.; Takahashi, M.; Kobayashi, T.; Suzuki, M.; Nakanishi, H.; Mori, S.; Nishizawa, N.K. Identification and localisation of the rice nicotianamine aminotransferase gene OsNAAT1 expression suggests the site of phytosiderophore synthesis in rice. Plant Mol. Biol. 2008, 66, 193-203. [CrossRef]

28. Bashir, K.; Inoue, H.; Nagasaka, S.; Takahashi, M.; Nakanishi, H.; Mori, S.; Nishizawa, N.K. Cloning and characterization of deoxymugineic acid synthase genes from graminaceous plants. J. Biol. Chem. 2006, 281, 32395-32402. [CrossRef]

29. Nozoye, T.; Nagasaka, S.; Kobayashi, T.; Takahashi, M.; Sato, Y.; Sato, Y.; Uozumi, N.; Nakanishi, H.; Nishizawa, N.K. Phytosiderophore efflux transporters are crucial for iron acquisition in graminaceous plants. J. Biol. Chem. 2011, 286, 5446-5454. [CrossRef]

30. Nozoye, T.; Nagasaka, S.; Kobayashi, T.; Sato, Y.; Uozumi, N.; Nakanishi, H.; Nishizawa, N.K. The phytosiderophore efflux transporter TOM2 is involved in metal transport in rice. J. Biol. Chem. 2015, 290, 27688-27699. [CrossRef]

31. Koike, S.; Inoue, H.; Mizuno, D.; Takahashi, M.; Nakanishi, H.; Mori, S.; Nishizawa, N.K. OsYSL2 is a rice metal-nicotianamine transporter that is regulated by iron and expressed in the phloem. Plant J. 2004, 39, 415-424. [CrossRef] [PubMed]

32. Ishimaru, Y.; Masuda, H.; Bashir, K.; Inoue, H.; Tsukamoto, T.; Takahashi, M.; Nakanishi, H.; Aoki, N.; Hirose, T.; Ohsugi, R.; et al. Rice metal-nicotianamine transporter, OsYSL2, is required for the long-distance transport of iron and manganese. Plant J. 2010, 62, 379-390. [CrossRef] [PubMed]

33. Senoura, T.; Sakashita, E.; Kobayashi, T.; Takahashi, M.; Aung, M.S.; Masuda, H.; Nakanishi, H.; Nishizawa, N.K. The iron-chelate transporter OsYSL9 plays a role in iron distribution in developing rice grains. Plant Mol. Biol. 2017, 95, 375-387. [CrossRef] [PubMed]

34. Zhang, C.; Shinwari, K.I.; Luo, L.; Zheng, L. OsYSL13 is involved in iron distribution in rice. Int. J. Mol. Sci. 2018, 19, 3537. [CrossRef] [PubMed] 
35. Inoue, H.; Kobayashi, T.; Nozoye, T.; Takahashi, M.; Kakei, Y.; Suzuki, K.; Nakazono, M.; Nakanishi, H.; Mori, S.; Nishizawa, N.K. Rice OsYSL15 is an iron-regulated iron(III)-deoxymugineic acid transporter expressed in the roots and is essential for iron uptake in early growth of the seedlings. J. Biol. Chem. 2009, 284, 3470-3479. [CrossRef]

36. Kakei, Y.; Ishimaru, Y.; Kobayashi, T.; Yamakawa, T.; Nakanishi, H.; Nishizawa, N.K. OsYSL16 plays a role in the allocation of iron. Plant Mol. Biol. 2012, 79, 583-594. [CrossRef]

37. Aoyama, T.; Kobayashi, T.; Takahashi, M.; Nagasaka, S.; Usuda, K.; Kakei, Y.; Ishimaru, Y.; Nakanishi, H.; Mori, S.; Nishizawa, N.K. OsYSL18 is a rice iron(III)-deoxymugineic acid transporter specifically expressed in reproductive organs and phloem of lamina joints. Plant Mol. Biol. 2009, 70, 681-692. [CrossRef]

38. Inoue, H.; Mizuno, D.; Takahashi, M.; Nakanishi, H.; Mori, S.; Nishizawa, N.K. A rice FRD3-like (OsFRDL1) gene is expressed in the cells involved in long-distance transport. Soil Sci. Plant Nutr. 2004, 50, 1133-1140. [CrossRef]

39. Ishimaru, Y.; Kakei, Y.; Shimo, H.; Bashir, K.; Sato, Y.; Sato, Y.; Uozumi, N.; Nakanishi, H.; Nishizawa, N.K. A rice phenolic efflux transporter is essential for solubilizing precipitated apoplasmic iron in the plant stele. J. Biol. Chem. 2011, 286, 24649-24655. [CrossRef]

40. Bashir, K.; Ishimaru, Y.; Shimo, H.; Kakei, Y.; Senoura, T.; Takahashi, R.; Sato, Y.; Sato, Y.; Uozumi, N.; Nakanishi, H.; et al. Rice phenolics efflux transporter 2 (PEZ2) plays an important role in solubilizing apoplasmic iron. Soil Sci. Plant Nutr. 2011, 57, 803-812. [CrossRef]

41. Kobayashi, T.; Ogo, Y.; Itai, R.N.; Nakanishi, H.; Takahashi, M.; Mori, S.; Nishizawa, N.K. The transcription factor IDEF1 regulates the response to and tolerance of iron deficiency in plants. Proc. Natl. Acad. Sci. USA 2007, 104, 19150-19155. [CrossRef]

42. Kobayashi, T.; Itai, R.N.; Ogo, Y.; Kakei, Y.; Nakanishi, H.; Takahashi, M.; Nishizawa, N.K. The rice transcription factor IDEF1 is essential for the early response to iron deficiency, and induces vegetative expression of late embryogenesis abundant genes. Plant J. 2009, 60, 948-961. [CrossRef]

43. Ogo, Y.; Kobayashi, T.; Itai, R.N.; Nakanishi, H.; Kakei, Y.; Takahashi, M.; Toki, S.; Mori, S.; Nishizawa, N.K. A novel NAC transcription factor, IDEF2, that recognizes the iron deficiency-responsive element 2 regulates the genes involved in iron homeostasis in plants. J. Biol. Chem. 2008, 238, 13407-13417. [CrossRef]

44. Ogo, Y.; Itai, R.N.; Nakanishi, H.; Inoue, H.; Kobayashi, T.; Suzuki, M.; Takahashi, M.; Mori, S.; Nishizawa, N.K. Isolation and characterization of IRO2, a novel iron-regulated bHLH transcription factor in graminaceous plants. J. Exp. Bot. 2006, 57, 2867-2878. [CrossRef]

45. Zheng, L.; Ying, Y.; Wang, L.; Wang, F.; Whelan, J.; Shou, H. Identification of a novel iron regulated basic helix-loop-helix protein involved in Fe homeostasis in Oryza sativa. BMC Plant Biol. 2010, 10, 166. [CrossRef]

46. Kobayashi, T.; Ozu, A.; Kobayashi, S.; An, G.; Jeon, J.S.; Nishizawa, N.K. OsbHLH058 and OsbHLH059 transcription factors positively regulate iron deficiency responses in rice. Plant Mol. Biol. 2019, 101, 471-486. [CrossRef]

47. Zhang, H.; Li, Y.; Pu, M.; Xu, P.; Liang, G.; Yu, D. Oryza sativa POSITIVE REGULATOR OF IRON DEFICIENCY RESPONSE 2 (OsPRI2) and OsPRI3 are involved in the maintenance of Fe homeostasis. Plant Cell Environ. 2019. [CrossRef]

48. Zhang, H.; Li, Y.; Yao, X.; Liang, G.; Yu, D. POSITIVE REGULATOR OF IRON HOMEOSTASIS1, OsPRI1, facilitates iron homeostasis. Plant Physiol. 2017, 175, 543-554. [CrossRef]

49. Wang, L.; Ying, Y.; Narsai, R.; Ye, L.; Zheng, L.; Tian, J.; Whelan, J.; Shou, H. Identification of OsbHLH133 as a regulator of iron distribution between roots and shoots in Oryza sativa. Plant Cell Environ. 2013, 36, 224-236. [CrossRef]

50. Wang, S.; Li, L.; Ying, Y.; Wang, J.; Shao, J.F.; Yamaji, N.; Whelan, J.; Ma, J.F.; Shou, H. A transcription factor OsbHLH156 regulates Strategy II iron acquisition through localizing IRO2 to the nucleus in rice. New Phytol. 2019. [CrossRef]

51. Kobayashi, T.; Nagasaka, S.; Senoura, T.; Itai, R.N.; Nakanishi, H.; Nishizawa, N.K. Iron-binding haemerythrin RING ubiquitin ligases regulate plant iron responses and accumulation. Nat. Commun. 2013, 4, 2792. [CrossRef]

52. Zhang, L.; Nakanishi Itai, R.; Yamakawa, T.; Nakanishi, H.; Nishizawa, N.K.; Kobayashi, T. The bowman-birk trypsin inhibitor IBP1 interacts with and prevents degradation of IDEF1 in rice. Plant Mol. Biol. Rep. 2014, 32, 841-851. [CrossRef] 
53. Yang, A.; Zhang, W.-H. A small GTPase, OsRab6a, is involved in the regulation of iron homeostasis in rice. Plant Cell Physiol. 2016, 57, 1271-1280. [CrossRef]

54. Yang, A.; Li, Y.; Xu, Y.; Zhang, W.-H. A receptor-like protein RMC is involved in regulation of iron acquisition in rice. J. Exp. Bot. 2013, 64, 5009-5020. [CrossRef]

55. Tan, S.; Liu, F.; Pan, X.X.; Zang, Y.P.; Jin, F.; Zu, W.X.; Qi, X.T.; Xiao, W.; Yin, L.P. CSN6, a subunit of the COP9 signalosome, is involved in early response to iron deficiency in Oryza sativa. Sci. Rep. 2016, 6. [CrossRef]

56. Grillet, L.; Lan, P.; Li, W.; Mokkapati, G.; Schmidt, W. IRON MAN is a ubiquitous family of peptides that control iron transport in plants. Nat. Plants 2018, 4, 953-963. [CrossRef]

57. Romheld, V.; Marschner, H. Genotypical differences among graminaceous species in release of phytosiderophores and uptake of iron phytosiderophores. Plant Soil 1990, 123, 147-153. [CrossRef]

58. Itai, R.N.; Ogo, Y.; Kobayashi, T.; Nakanishi, H.; Nishizawa, N.K. Rice genes involved in phytosiderophore biosynthesis are synchronously regulated during the early stages of iron deficiency in roots. Rice 2013, 6, 16. [CrossRef]

59. Kobayashi, T.; Suzuki, M.; Inoue, H.; Itai, R.N.; Takahashi, M.; Nakanishi, H.; Mori, S.; Nishizawa, N.K. Expression of iron-acquisition-related genes in iron-deficient rice is co-ordinately induced by partially conserved iron-deficiency-responsive elements. J. Exp. Bot. 2005, 56, 1305-1316. [CrossRef]

60. Kobayashi, T.; Nishizawa, N.K. Iron uptake, translocation, and regulation in higher plants. Annu. Rev. Plant Biol. 2012, 63, 131-152. [CrossRef]

61. Curie, C.; Panaviene, Z.; Loulergue, C.; Dellaporta, S.L.; Briat, J.F.; Walke, E.L. Maize yellow stripe1 encodes a membrane protein directly involved in Fe(III) uptake. Nature 2001, 409, 346-349. [CrossRef]

62. Ogo, Y.; Kakei, Y.; Itai, R.N.; Kobayashi, T.; Nakanishi, H.; Takahashi, H.; Nakazono, M.; Nishizawa, N.K. Spatial transcriptomes of iron-deficient and cadmium-stressed rice. New Phytol. 2014, 201, 781-794. [CrossRef]

63. Bughio, N.; Yamaguchi, H.; Nishizawa, M.K.; Nakanishi, H.; Mori, S. Cloning an iron-regulated metal transporter from rice. J. Exp. Bot. 2001, 53, 1677-1682. [CrossRef]

64. Li, L.; Ye, L.; Kong, Q.; Shou, H. A vacuolar membrane ferric-chelate reductase, OsFRO1, alleviates Fe toxicity in rice (Oryza sativa L.). Front. Plant Sci. 2019, 10, 700. [CrossRef]

65. Kobayashi, T.; Itai, R.N.; Nishizawa, N.K. Iron deficiency responses in rice roots. Rice 2014, 7, 27. [CrossRef]

66. Brown, J.C.; Chaney, R. Effect of iron on the transport of citrate into the xylem of soybean and tomatoes. Plant Physiol. 1971, 47, 836-840. [CrossRef]

67. Tiffin, L.O. Iron translocation II. Citrate/iron ratios in plant stem exudates. Plant Physiol. 1966, 41, 515-518. [CrossRef]

68. Takahashi, M.; Terada, Y.; Nakai, I.; Nakanishi, H.; Yoshimura, E.; Mori, S.; Nishizawa, N.K. Role of nicotianamine in the intracellular delivery of metals and plant reproductive development. Plant Cell 2003, 15, 1263-1280. [CrossRef]

69. Durrett, T.P.; Gassmann, W.; Rogers, E. The FRD3-mediated efflux of citrate into the root vasculature is necessary for efficient iron translocation. Plant Physiol. 2007, 144, 197-205. [CrossRef]

70. Yokosho, K.; Yamaji, N.; Ueno, D.; Mitani, N.; Ma, J.F. OsFRDL1 is a citrate transporter required for efficient translocation of iron in rice. Plant Physiol. 2009, 149, 297-305. [CrossRef]

71. Yokosho, K.; Yamaji, N.; Ma, J.F. OsFRDL1 expressed in nodes is required for distribution of iron to grains in rice. J. Exp. Bot. 2016, 67, 5485-5494. [CrossRef]

72. Lee, S.; Chiecko, J.C.; Kim, S.A.; Walker, E.L.; Lee, Y.; Guerinot, M.L.; An, G. Disruption of OsYSL15 leads to iron inefficiency in rice plants. Plant Physiol. 2009, 150, 786-800. [CrossRef]

73. Lee, S.; Ryoo, N.; Jeon, J.S.; Guerinot, M.L.; An, G. Activation of rice Yellow Stripe1-Like 16 (OsYSL16) enhances iron efficiency. Mol. Cells 2012, 33, 117-126. [CrossRef]

74. Kobayashi, T.; Ogo, Y.; Aung, M.S.; Nozoye, T.; Itai, R.N.; Nakanishi, H.; Yamakawa, T.; Nishizawa, N.K. The spatial expression and regulation of transcription factors IDEF1 and IDEF2. Ann. Bot. 2010, 105, 1109-1117. [CrossRef]

75. Kobayashi, T.; Itai, R.N.; Aung, M.S.; Senoura, T.; Nakanishi, H.; Nishizawa, N.K. The rice transcription factor IDEF1 directly binds to iron and other divalent metals for sensing cellular iron status. Plant J. 2012, 69, 81-91. [CrossRef]

76. Aung, M.S.; Kobayashi, T.; Masuda, H.; Nishizawa, N.K. Rice HRZ ubiquitin ligases are crucial for the response to excess iron. Physiol. Plantarum 2018, 163, 282-296. [CrossRef] 
77. Ogo, Y.; Itai, R.N.; Kobayashi, T.; Aung, M.S.; Nakanishi, H.; Nishizawa, N.K. OsIRO2 is responsible for iron utilization in rice and improves growth and yield in calcareous soil. Plant Mol. Biol. 2011, 75, 593-605. [CrossRef]

78. Ogo, Y.; Itai, R.N.; Nakanishi, H.; Kobayashi, T.; Takahashi, M.; Mori, S.; Nishizawa, N.K. The rice bHLH protein OsIRO2 is an essential regulator of the genes involved in Fe uptake under Fe-deficient conditions. Plant J. 2007, 51, 366-377. [CrossRef]

79. Zhu, J.Y.; Sae-Seaw, J.; Wang, Z.Y. Brassinosteroid signalling. Development 2013, 140, 1615-1620. [CrossRef]

80. Wang, B.; Li, Y.; Zhang, W.-H. Brassinosteroids are involved in response of cucumber (Cucumis sativus) to iron deficiency. Ann. Bot. 2012, 110, 681-688. [CrossRef]

81. Wang, B.; Li, G.; Zhang, W.-H. Brassinosteroids are involved in Fe homeostasis in rice (Oryza sativa L.). J. Exp. Bot. 2015, 66, 2749-2761. [CrossRef]

82. Claeys, H.; De Bodt, S.; Inzé, D. Gibberellins and DELLAs: Central nodes in growth regulatory networks. Trends Plant Sci. 2014, 19, 231-239. [CrossRef]

83. Matsuoka, K.; Furukawa, J.; Bidadi, H.; Asahina, M.; Yamaguchi, S.; Satoh, S. Gibberellin-induced expression of Fe uptake-related genes in Arabidopsis. Plant Cell Physiol. 2013, 55, 87-98. [CrossRef]

84. Wang, B.; Wei, H.; Xue, Z.; Zhang, W.-H. Gibberellins regulate iron deficiency-response by influencing iron transport and translocation in rice seedlings (Oryza sativa). Ann. Bot. 2017, 119, 945-956. [CrossRef]

85. Huang, H.; Liu, B.; Liu, L.; Song, S. Jasmonate action in plant growth and development. J. Exp. Bot. 2017, 68, 1349-1359. [CrossRef]

86. Turner, J.G.; Ellis, C.; Devoto, A. The jasmonate signal pathway. Plant Cell 2002, 14, 153-164. [CrossRef]

87. Maurer, F.; Müller, S.; Bauer, P. Suppression of Fe deficiency gene expression by jasmonate. Plant Physiol. Biochem. 2011, 49, 530-536. [CrossRef]

88. Yoshii, M.; Yamazaki, M.; Rakwal, R.; Kishi-Kaboshi, M.; Miyao, A.; Hirochika, H. The NAC transcription factor RIM1 of rice is a new regulator of jasmonate signaling. Plant J. 2010, 61, 804-815. [CrossRef]

89. Kobayashi, T.; Itai, R.N.; Senoura, T.; Oikawa, T.; Ishimaru, Y.; Ueda, M.; Nakanishi, H.; Nishizawa, N.K. Jasmonate signaling is activated in the very early stages of iron deficiency responses in rice roots. Plant Mole. Biol. 2016, 91, 533-547. [CrossRef]

90. Wang, K.L.C.; Li, H.; Ecker, J.R. Ethylene biosynthesis and signaling networks. Plant Cell 2002, 14, $131-151$. [CrossRef]

91. Lucena, C.; Romera, F.J.; Garcia, M.J.; Alcantara, E.; Perez-Vicente, R. Ethylene participates in the regulation of Fe deficiency responses in Strategy I plants and in rice. Front. Plant Sci. 2015, 6, 1056. [CrossRef] [PubMed]

92. Wu, J.; Wang, C.; Zheng, L.; Wang, L.; Chen, Y.; Whelan, J.; Shou, H. Ethylene is involved in the regulation of iron homeostasis by regulating the expression of iron-acquisition-related genes in Oryza sativa. J. Exp. Bot. 2011, 62, 667-674. [CrossRef] [PubMed]

93. Zheng, L.; Huang, F.; Narsai, R.; Wu, J.; Giraud, E.; He, F.; Cheng, L.; Wang, F.; Wu, P.; Whelan, J.; et al. Physiological and transcriptome analysis of Iron and phosphorus interaction in rice seedlings. Plant Physiol. 2009, 151, 262-274. [CrossRef] [PubMed]

94. Chen, P.F.; Chen, L.; Jiang, Z.R.; Wang, G.P.; Wang, S.H.; Ding, Y.F. Sucrose is involved in the regulation of iron deficiency responses in rice (Oryza sativa L.). Plant Cell Rep. 2018, 37, 789-798. [CrossRef] [PubMed]

95. Hammond, J.P.; White, P.J. Sucrose transport in the phloem: Integrating root responses to phosphorus starvation. J. Exp. Bot. 2008, 59, 93-109. [CrossRef] [PubMed]

96. Liu, K.; Yue, R.; Yuan, C.; Liu, J.; Zhang, L.; Sun, T.; Yang, Y.; Tie, S.; Shen, C. Auxin signaling is involved in iron deficiency-induced photosynthetic inhibition and shoot growth defect in rice (Oryza sativa L.). J. Plant Biol. 2015, 58, 391-401. [CrossRef]

97. Xu, Y.; Zhang, S.; Guo, H.; Wang, S.; Xu, L.; Li, C.; Qian, Q.; Chen, F.; Geisler, M.; Qi, Y.; et al. OsABCB14 functions in auxin transport and iron homeostasis in rice (Oryza sativa L.). Plant J. 2014, 79, 106-117. [CrossRef]

98. Qi, Y.; Wang, S.; Shen, C.; Zhang, S.; Chen, Y.; Xu, Y.; Liu, Y.; Wu, Y.; Jiang, D. OsARF12, a transcription activator on auxin response gene, regulates root elongation and affects iron accumulation in rice (Oryza sativa). New Phytol. 2012, 193, 109-120. [CrossRef]

99. Shen, C.; Yue, R.; Sun, T.; Zhang, L.; Yang, Y.; Wang, H. OsARF16, a transcription factor regulating auxin redistribution, is required for iron deficiency response in rice (Oryza sativa L.). Plant Sci. 2015, 231, 148-158. [CrossRef] 
100. Buet, A.; Galatro, A.; Ramos-Artuso, F.; Simontacchi, M. Nitric oxide and plant mineral nutrition: Current knowledge. J. Exp. Bot. 2019, 70, 4461-4476. [CrossRef]

101. Sun, H.; Feng, F.; Liu, J.; Zhao, Q. The interaction between auxin and nitric oxide regulates root growth in response to iron deficiency in rice. Front. Plant Sci. 2017, 8, 2169. [CrossRef] [PubMed]

102. Zhu, C.Q.; Zhang, J.H.; Zhu, L.F.; Abliz, B.; Zhong, C.; Bai, Z.G.; Hu, W.J.; Sajid, H.; James, A.B.; Cao, X.C.; et al. $\mathrm{NH}_{4}{ }^{+}$facilitates iron reutilization in the cell walls of rice (Oryza sativa) roots under iron-deficiency conditions. Environ. Exp. Bot. 2018, 151, 21-31. [CrossRef]

103. Tuteja, N. Abscisic acid and abiotic stress signaling. Plant Signal. Behav. 2007, 2, 135-138. [CrossRef] [PubMed]

104. Séguéla, M.; Briat, J.F.; Vert, G.; Curie, C. Cytokinins negatively regulate the root iron uptake machinery in Arabidopsis through a growth-dependent pathway. Plant J. 2008, 55, 289-300. [CrossRef] [PubMed]

105. Shen, C.; Yang, Y.; Liu, K.; Zhang, L.; Guo, H.; Sun, T.; Wang, H. Involvement of endogenous salicylic acid in iron-deficiency responses in Arabidopsis. J. Exp. Bot. 2016, 67, 4179-4193. [CrossRef]

(C) 2019 by the authors. Licensee MDPI, Basel, Switzerland. This article is an open access article distributed under the terms and conditions of the Creative Commons Attribution (CC BY) license (http://creativecommons.org/licenses/by/4.0/). 